\title{
HUMAN RESOURCE MANAGERS VIEWS ON IMPLEMENTING WORK-LIFE BALANCE
}

\author{
Lisa Mohn \\ Department of Sociology and Social Policy \\ University of Waikato
}

\begin{abstract}
This paper focuses on the views of Human Resource (HR) managers about the implementation of work life balance (WLB) initiatives. Increasingly, WLB has become an important part of employment relations discussion and knowledge. The literature presents two key themes in terms of how this is implemented in practice. Firstly there was a corporate theme, where WLB is developed and applied from within the organisation. In the second theme WLB is developed and applied in tripartite partnership. The literature showed the New Zealand (NZ) experience is confused as to which path it is following. Thus, the purpose of this study was to explore the views of HR managers in NZ government funded tertiary institutions about the implementation of WLB practices. The research involved 3 in-depth, semi-structured interviews, which were then transcribed, analysed and compared until stable categories emerged. The findings reflected the confusion found in the literature. Approaches and knowledge of WLB were standardised and essentially uniform; there was much pride and satisfaction in achievements, both individual and corporately; and despite being government funded, the organisations reflected a corporatist theme in their approach to WLB. In summary, regardless of the rhetoric of WLB as positive to workers regaining balance in their lives, the research showed in practice it was 'a wolf in sheep's clothing' -- more beneficial for the organisations in terms of increasing worker productivity, than for the workers
\end{abstract}

\section{Introduction}

Amongst my various experiences in the workforce, one particular element of work culture struck me as particularly odd; the apparent expectation of living to work, and not the other way around. It is expected that your job, the company and your loyalty to the company should prioritised over anything else. I kept this phenomenon in the back of my head, until recently, when I had the opportunity to develop and engage in research on the question of WLB culture in New Zealand. Increasingly, WLB has become an important part of employment relations knowledge and practice; the purpose of this paper is to explore the form WLB initiatives assume in practice. The paper first presents two key themes found in the literature concerning WLB, the corporate theme and the tripartite theme. This is followed by a critique of that literature, noting key flaws and silences in the literature. The methodology and research technique are then briefly explained, followed by a presentation of selected findings. Finally, there is a brief discussion of the findings, including comparison to the literature, and possibilities for further research.

\section{Literature Review}

Various literature on WLB was used to gain knowledge of WLB in practice. Websites concerning WLB such as worklifebalance.com and worklifebalance.org, were also used to source further insight into the conceptions and initiatives promoted in terms of WLB. The literature presents quite similar objectives and initiatives, and therefore seems to take a very similar shape, regardless of the environment. However, two key approaches to WLB did emerge, each with a different key proponent, purpose, and expected outcome. A key variant in this is the role of government in the promotion of WLB in the workplace.

The first approach is the corporate, or enterprise theme. Here, WLB is initiated by an individual company with a purpose of competitive advantage; examples are most commonly found in the United States. This competitive advantage model is motivated by several key factors. Firstly, the company's ability to recruit the best talent. Secondly, the company's ability to retain skilled workers. These two factors appear repeatedly in the literature as primary motivators for WLB programmes in private enterprise (Christensen, 1997; Joshi, Leichne, Melanson, Pruna, Sager, \& Story, et.al,. 2002; Hoar, \& KirwanTaylor, 2004; Murphy, 1996). To a lesser extent, a third key factor is where a company offers WLB in order to be flexible to meet customer service needs. This, hypothetically, then enables the worker and the customer both to have satisfaction in meeting their individual needs.

These motivating factors of recruitment, retention, and flexibility are then promoted through a series of common initiatives. One, perks. A company would offer a company car, subsidised gym memberships, or bonus schemes to attract skilled workers (Clements, Hobman, Rosier, \& Tweedy; Joshi et.al., 2002). Two, job-sharing or part-time work. These initiatives are a part of 'familyfriendly' policies, particularly for working mothers, to enable flexibility in hours and job demands. Concrete employment rights and benefit retention are key elements 
here as they allow career development, and job security (Christensen, 1997; Clements, Hobman, Rosier, \& Tweedy; Hoar, \& Kirwan-Taylor, 2004; Joshi et.al,. 2002; Murphy, 1996). Three, leave entitlements. This included 'Carers leave' enabling time off to care for a relative when needed and taking a sabbatical or 'career break', while still retaining job security (Joshi et.al,. 2002; Murphy, 1996).

The fourth common initiative is providing childcare or after-school care facilities, or subsidised care (Christensen, 1997; Joshi, et.al,. 2002). Five, flexibility in work location, i.e. telecommuting (Clements, Hobman, Rosier, \& Tweedy; Joshi et.al,. 2002; Murphy, 1996). Six, recognition by management of effort and achievement. This could be achieved through awards schemes, bonus schemes, or simply through verbal (or email) affirmation (Christensen, 1997; Hoar, \& KirwanTaylor, 2004). The motivation and anticipated outcomes of WLB schemes within a competitive advantage framework are intertwined. Initiatives aimed at the recruitment and retainment of skilled employee's, are also seen to lead to greater employee loyalty and job satisfaction. These schemes are given as vital elements to company innovation and growing their market share.

The schemes used in the second key approach to WLB are very similar to the corporate theme, however, the motivation and key proponents are significantly different. The second key approach found in the literature was a tripartite theme (European Trade Union Institute, 1995; Joshi et.al,. 2002; New Zealand Council of Trade Unions, 2003). This approach is most common in Europe, and New Zealand seems to be following this pattern closely. There is a tripartite relationship between governments, employers, and unions, who then endeavour to successfully and co-operatively develop and implement WLB initiatives. This tripartite theme is seen to have a social responsibility agenda and is primarily motivated by increased diversity now within the workforce (Joshi et.al,. 2002; NZCTU, 2003). The more diverse nature now requires increased flexibility in working conditions and arrangements, and the old more rigid models are becoming less able to meet modern demands.

The key initiatives in this theme are: (1) Flexible hours. (NZCTU, 2003; ETUI, 1995; Joshi et.al,. 2002) (2) Leave entitlements. (NZCTU, 2003; Joshi et.al,. 2002). (3) Childcare and after-school care facilities or subsidies. (ibid). The catch phrases here are 'affordable', 'accessible', and 'high quality' (NZCTU, 2003). (4) Flexibility in location. (Joshi et.al,. 2002). (5) The initiative unique to this approach is in the role of collective bargaining. Unions in this model can negotiate for the elements of WLB specific to the needs of their members (NZCTU, 2003; ETUI, 1995).

The goals promoted in the tripartite theme are similar to those of the corporate theme - job satisfaction, staff recruitment and retention, increased staff loyalty, and reduced absentecism, however, there are differences. Unions and Governments in this theme are intended to be exemplary employers, demonstrating WLB in practice. The goals promoted are similar to those of the corporate theme - job satisfaction, staff recruitment and retention, increased staff loyalty, and reduced absenteeism, however, there are differences. The tripartite theme is intended to be about social responsibility and therefore promoting the greater good. It also seems more about economic growth, and consequently higher standards of living overall. Overall, flexibility is a repeated theme in the literature, whatever the theme, as is the growing need for diversity in work practices, and the growing demand for job satisfaction.

\section{Critique - Where the Issues Lie}

The first significant limitation to emerge from the literature was the vagueness surrounding the exact meaning of WLB, and how it is to be applied. The obvious interpretation would be a balancing of work and life outside of work; however that understanding is very non-specific with respect to culture, gender and individual circumstances. Work was the more commonly described of the two elements, being generally understood as paid employment within a capitalist, western European context. Life was the less described element of the pair. The most common reference to life outside of work was given to family, more specifically to childcare and parental responsibilities. The problem in defining WLB most likely stems from the very different needs of different individuals, cultures, workplaces, and industries. Cultural and gender issues here are necessarily dominant, particularly in the tripartite theme, due to the historical homogenising, and oppressing nature of work. Consequently, due to the various needs to be met flexibility is a term that is constantly used with WLB.

Another significant limitation is the lack of commentary on whether work and life are actually separate entities at all. In a capitalist society, work is an inherent part of our lives therefore it could be considered that to work is to live. A Marxist critique by Shorthose (2004) comments on the fact that WLB only plays within the boundaries of the capitalist mode of production, it does not attempt to reposition them. Is then the problem with WLB really about job satisfaction, or is it more to do with the alienating experience of work itself? Though this critique is, in my opinion, quite valid, it is also naive or unrealistic to think that the nature of work and society will ever change that drastically. It would seem to me that the WLB campaign has rightly taken the pragmatic approach in trying to reconcile (to the best of its ability) the conflicting factors inherent in the nature of work today.

There are also issues surrounding the increasingly blurred barriers between work and life outside of work. On the one hand, being able to work at home or from remote locations has offered flexibility and a sense of autonomy for people. On the other hand, it offers increasing intrusion into their 'personal time', adding unnecessary stress and anxiety. The only way that the literature seems to deal with this issue is through its mantra of 'flexibility'. A corresponding element and possible solution to this offered in some of the literature, in the responsibility of the individual. Not all of the responsibility for job satisfaction should be placed on the 
nature of work and work structures (Joshi et.al,. 2002; Hoar, \& Kirwan-Taylor, 2004).

Identifying WLB issues and solutions in New Zealand has really only begun in the last few years. The New Zealand situation seems to have followed the European model of social responsibility, with several unions leading the way in promoting the campaign i.e. the NZCTU, the Public Service Association and FINSEC. The government funded EEO Trust has also taken up the campaign and recognises businesses with outstanding EEO and WLB policies with annual awards (CTU, 2003; Clements, Hobman, Rosier, \& Tweedy). However there is need for consolidation in the New Zealand context on what exactly WLB is, as the unions seem to have taken a tripartite approach, while the EEO Trust seems to have taken a more corporate approach. If there is to be any success in addressing issues and finding solutions, particularly for the New Zealand context, there needs to be at least some agreement.

\section{Methodology}

Given the above lack of clear understanding of what WLB is in the New Zealand context, the research question was then: "What are the views of Human Resource practitioners in government-funded tertiary institutions about the implementation \& practice of current WLB policies?"

The research project took a qualitative approach. This approach allows flexibility in exploring the various forms and initiatives of WLB, and can also reveal hidden assumptions and motivations behind the choices of initiatives made. The research involved in-depth, semistructured interviews with 3 respondents - Alex, Chris and Jamie. The respondents were all in Human Resource (HR) departments of tertiary education institutions, based in the Waikato. Each respondent was in a development advisory role, which included the development and implementation of WLB initiatives. The profile was chosen based on an assumption that government-funded organisations would be well informed about issues of social policy and employment relations. This assumption also took into account the recent emphasis placed on WLB in recent government policy and organisations.

The interviews with Alex and Chris took place at their location of work and the interview with Jamie was by phone. Each interview lasted approximately 45 minutes and was recorded. A questionnaire was developed with questions based around basic themes: how each respondent conceptualised WLB; why and how initiatives were implemented in their organisation; and what the outcomes of those initiatives were.

The data from each interview was then transcribed, analysed and compared until stable categories emerged. This study makes no attempt to be representative, nor does it make any generalisations about the current state of WLB within government-funded organisations. The research is exploratory and provides a glimpse into the attitudes and intentions behind WLB initiatives.

\section{Selected Findings}

The discussions revealed several commonalities and themes which have been organised into three predominant groups. Analysis of the transcripts exposed a sense of standardisation, pride and accomplishment, and that WLB is really about the organisation.

\section{It's Standardised}

There was a sense of standardisation in the initiatives and conceptions held by the respondents. There was the standardisation of:

WLB as a concept. WLB was seen as andividually decided balance that took account of the wide array of needs and responsibilities in people's lives. It was given by Alex as "Treating people holistically. Recognising that people are more than just a resource to be used for 8.5 hours or 7.5 hours a day or what ever, and then spat out at the end." For Chris it was "Not necessarily that you have $50 \%$ at work and $50 \%$ at home, because I feel that everybody is different in what the percentage is... it's that people feel as though for them the balance is right ... It's also meaning that when staff leave here they have got the energy and time to spend with their family." This same sense of the holistic nature of WLB was echoed in Jamie's comments. "Family and the other roles that a person fulfills in their life, just as important as their role as an employee...I'm always looking at how does the person manage all those obligations and requirements, and still remain complete."

The same terms were used to describe the benefits of WLB, particularly in terms of the perceived benefits. In response to a question about the advantages of WLB Alex gave this answer "Loyal staff, greater staff retention, less loss of productivity through people being unwell or having problems." Chris stated that "Retention is huge." Retention again was mentioned by Jamie, when asked about what they were trying to achieve. "Staff retention. Thereby retaining our knowledge."

Sources of information. The sources used for WLB and other HR topics were very uniform as well. The three respondents had association with the Human Resource Institute New Zealand, and other common sources included the New Zealand Institute of Management and the Employers and Manufacturers Association. Other sources included journals such as 'Employment Today', and providers such as Workplace Support and EAP Services.

Lacking creativity. The initiatives used were derived from external sources (as given above), be they programmes other organisations had in place (nationally and internationally), or from literature surrounding WLB. Commonly given initiatives were: Employee Assistance Programme (EAP), insurances, flexible hours, familyfriendly policies, subsidised gym memberships, health centres, childcare, and staff development programmes. One respondent also mentioned they had developed an intranet website to provide WLB information for all staff. This was a minor point of difference amongst the 
predominant standardisation however. Throughout this there was also a sense that the respondent or their departments did not seek out the issues, and again sort solutions from and existing pool of information.

\section{It gives Satisfaction and Pride}

There was a sense of pride and accomplishment in implementing WLB initiatives in their organisation. Pride and accomplishment in:

Their organisation as an exemplary employer. "We are a bit of a flagship. What ever happens with this [organisation], everybody notices - the government, the media. We do have a bit of a public profile to maintain, and to be a good employer." This sense of responsibility permeates through the discussions. Another respondent talked about how their organisation has "lead the way"; that they have always been ahead, particularly in terms of legislative requirements for the workplace. "We were the first organisation to have a harassment policy, before it was required. I think we've always lead the way in those sort of family-friendly people focussed, the well-being of individuals type policies... We do push the fact we have all these people friendly policies, and I think people like to come into an organisation where they feel like they're being recognised as an individual, and that they're being recognised outside of the workplace, that they're not just a number, or a resource to be used up." (Alex)

Their individual accomplishments. There was a feeling of pride at the respondents own role in developing initiatives. One respondent spoke of one initiative that they were particularly proud of - a time-out room for breastfeeding mothers. "To me, if we've got one staff member who can come and breast feed her baby and express milk for her baby, then that's, I don't care. That's fine. That's all I need to feel as though it's been successful for me". Another respondent had an insurance initiative in the pipeline that they seemed proud to be developing. Amongst this, the element of personal investment as a prerequisite for the sense of pride, was noticeable.

The success of the strategies. The respondents were asked about whether they thought the initiatives were successful or not, and there was a uniform sense that they were. However the respondents also noted that there was no true way to quantify, or empirically measure that success. "[Success] depends on what you're trying to achieve, it's probably beyond the simple recruitment and retention... which are measurable, its more around peoples attitudes, how they feel about their organisation. And 1 think in that respect, it is [successful]. Because you ask most people is the [organisation] a good employer? Most people will say yeah, yes it is." (Alex). One of the respondents had done a survey to get feedback on specific initiatives and received a good response from that, with areas highlighted for improvement. Another mention was that success depended much on the support of management. "Where a manager has a full working knowledge of [initiatives], it's effective." (Jamie). "To be really successful it has to come from the top. There has to be, that kind of buy in from there."(Chris).

\section{It's about the Organisation}

Regardless of the rhetoric on WLB as being about workers and enabling them to regain balance in their lives, the research showed in practice it is more about the organisation and being able to increase worker productivity. It's about:

'A wolf in sheep's clothing. The rhetoric around WLB talks of assisting workers in maintaining a balance however the overwhelming feeling from the respondents was actually the opposite. The word repeated time and again was productivity. When asked about what the advantages were for implementing WLB the answers uniformly quoted productivity. "If you have staff who are happy then you get more production it's win/win... [It's] that people feel that...they're happy with their life, that they're getting time for things out of work Whether that's friends, family... their interests, their home, their travel.... and also while at work they feel as though they're here doing something productive and they're working really effectively at work" (Chris). "The key advantage is productivity. As far as I'm concerned a worker who does not have to spend emotional energy worrying about other areas, is a more productive worker.... [there is a ] stronger sense of loyalty to the company, greater buy to our mission and value statements" (Jamie). "It's quite a strategic approach really, in terms of organisational goals, individual goals and getting a match between them.... So if we look after people, we're probably going to get better work out of them" (Alex).

This sense of being about the organisation is further reflected in an answer to a question about who primarily benefits from WLB initiatives - "If you have staff who are happy ...you're going to get more production. It's a win/win...If we've got happy staff then we've got a happy organisation. And I think if you've got happy staff we're more likely to meeting our organisational goals, and people are more likely to stay here, which is good for us." (Chris). WLB also facilitates 'best practice'. That is, the most streamlined, efficient business practice; implementation "I suppose [is] driven by "best practice"" (Alex).

Keeping up with the Jones'. There was also a sense that WLB had a strong element of image and self-promotion. "We're all are marketers." If workers are happy at work then "they will also tell other people about [the organisation]. Hey it's a great place to work!" (Chris). The organisation uses WLB for promotion; "We do push the fact we have all these people friendly policies" (Alex). This competition is not just limited to other publicly-funded organisations, but also includes competition for expert knowledge. To be an active player in the market, there is a realisation that their organisations at times can not offer remuneration to match the private sector, so WLB becomes an important selling point. "We acknowledge that we don't pay top of the market, so I guess this is some way of benefits to staff that has financial value to them" (Jamie). "Typically, we offer more." (Alex) This sub-theme is related to the previous sub-theme of pride in the organisation as an exemplary 
employer; that organisations are seen to be seen. "We do have a bit of a public profile to maintain" (Jamie).

\section{Discussion}

The literature presented a certain amount of confusion in the New Zealand context, as to which of the two differing themes applied more relevantly. The findings reflected this confusion. Possibly the most interesting characteristic was that despite the respondents coming from government funded tertiary institutions, the form WLB took there was closer to that of the corporate theme than it was to the tripartite. There is a notion of the organisations being exemplary employers, as is found in the literature for tripartite theme, and gestures to a role of social responsibility. However, the constant demand or motivation of increased productivity more closely mirrors the corporate theme. There was no sense of tripartite cooperation, the greater good, stimulating economic growth, or social cohesion. There was a role for unions within wider employment relations for at least two of the organisations, however, not in terms of WLB specifically. This was left primarily to the devices of the HR department; run by the organisation for the organisation. The focus seems entirely upon the organisation - what it can gain through WLB in terms of competitive advantage, increased productivity and market share. It is a key silence, the lack of anything referring to government practice or policy. Most likely it reflects the embedding of the 'New-Right' ideology within public sector; the forced kowtow to a competitive market model, as has been promoted in recent decades.

Another interesting characteristic was that despite the continual reference to productivity, the overall sentiment from the respondents was that WLB initiatives were beneficial for all. It appears almost unknown to them that in practice, it seems all about organisational gain. The sentiment of WLB being for workers impressed me as genuine - that they really sought to benefit the lives of workers around them, and believed they were. However, while there was this genuine concern for the welfare of the workers - both individually and within their wider social circle - there remained the need for cost-benefit analysis. Do the benefits outweigh the costs? This question seems to underpin the argument about WLB initiatives and again reflects the embedding of the market model. If WLB can't prove its worth in real terms, then there could be doubt as to its value overall. However, these underpinning concepts appear to remain in the background, with the well-being of workers still given as the dominant rational for WLB. This characteristic reflects again the literature and the vagueness found in the WLB concept. The element of work remained key to the focus.

The research showed an awareness of the issues surrounding the increasingly blurred barriers of work and life outside of work, more so than the literature would suggest. The EAP initiative particularly is an example of a strategy that acts to combat stresses that impact an individual's ability to work productively. This could suggest that practical experience is starting to inform theory and innovate new strategies for WLB. However, the research here may suggest that New Zealand is not apart of this creative process; merely content to rely on experience in overseas models. As a whole, WLB initiatives and strategies are seen as successful, but there is no sense of challenging the status quo. The concept in theory and in practice seems content to remain within the given capitalist market-driven boundaries. One aspect of WLB not well-explored to my knowledge, is whether or not WLB initiatives extent to part-time or temporary workers, and if not (an assumption), what impact does that have on their WLB?

\section{Conclusion}

This paper has presented an interpretation of the literature surrounding WLB. A critique was also offered raising some key issues of differing interpretations of the exact concept, paid works increasing intrusion into daily life via technology, and most importantly for this study, the confusion in the New Zealand context as to which path to follow - the tripartite, or corporate. This led then to the research on what form WLB takes in practice in New Zeaiand. The data collected suggests several things. Firstly, that there is a great deal of uniformity in WLB concepts, initiatives and sources of information. Secondly, that there is a great sense of pride and accomplishment in the organisation as an exemplary employer, in individual accomplishments, and in the general success of the initiatives. Thirdly, despite the rhetoric of WLB being for the workers, in practice it seems more like a 'wolf in sheep's clothing'; actually all about organisational gain. WLB strategies and initiatives seem perceived as a success, however there is no clear measure for this. It, in practice, seems a micro solution with no sense of challenging the status quo. 


\section{References}

Christensen, P.M. (1997). Toward a Comprehensive Work/Life Strategy. In S. Parasuraman, \& J. H. Greenhaus, (Eds.), Integrating Work and Family: Challenges and choices for a changing world. (pp. 25-37). Westport, Connecticut: Quorum Books.

Clements, E., Hobman, L., Rosier, P., \& Tweedy, R. Flexible Employment. Retrieved June 4, 2004, from http://www.eeotrust.org.nz/worklife/docx/ flexible_employment.doc.

European Trade Union Institute (1995). A Workingtime Policy for Jobs and an Improved Quality of Life. In R. Hoffmann, \& J. Lapeyre, (Eds.), A Time for Working, a Time for Living. (pp.228248). Documentation of the joint conference of the European Trade Union Confederation and the European Trade Union Institute, December 1994. Jointly Published by the ETUI and the Labour Research Department.

Hoar, R., \& Kirwan-Taylor, H. (2004). Work with Meaning. Management Today, May 2004. Retrieved May 31, 2004, from http://proquest. umi.com.ezproxy.waikato.ac.nz.
Joshi, S., Leichne, J., Melanson, K., Pruna, C., Sager, N., Story, C.J., \& Williams, K. (2002). Work-Life Balance...A Case of Social Responsibility or Competitive Advantage? Retrieved June 3, 2004, from http://www.worklifebalance.com.

Murphy, E. (1996). Flexible Work. Hemel Hempstead: Director Books.

New Zealand Council of Trade Unions (2003). WorkLife Balance: Executive summary. Discussion Paper, Biennial Conference 2003. Retrieved June 3, 2004, from http://www.union.org.nz/data/ general/files/worklife.pdf.

Shorthose, J. (2004). Like Summer and Good Sex: The limitation of the work-life balance campaign. Captial \& Class, Spring 2004 (Iss.82). Retrieved June 1, 2004, from http://proquest.umi.com. ezproxy.waikato.ac.nz

Wilson, M. (2003). A Proposed Approach to Stakeholder Engagement on Work-life Balance. From the Office of the Minister of Labour, to the Chair, Cabinet Economic Development Committee. Retrieved October 10, 2004, from http://www. dol.govt.nz/PDFs/cab\%20paper\%20worklife $\% 20 \mathrm{~b}$ alance 